\title{
The outcome of stroke: A six month follow-up study
}

\section{Abstract}

Background and objective: Stroke is an increasing problem in developing countries and is the principal cause of disability and dependency in the western world. This study aimed to find out the one- and six-month case fatality, dependency and recurrence rates of stroke in Erbil teaching hospitals.

Methods: This hospital-based prospective study included 293 stroke patients hospitalized in Erbil teaching hospitals from January $1^{\text {st }}, 2015$ through December $31^{\text {st }}, 2015$. Stroke was diagnosed by a consultant internist or neurologist and confirmed by brain CT-scan and/or MRI. Patients were followed-up for six months, then one- and six-month outcomes were measured including case-fatality, dependency and recurrences rates.

Results: The one and six month case fatality rates were $28.3 \%$ and $37.5 \%$, respectively. The rates in females $(33.3 \%, 42.6 \%$, respectively) were higher than that in males $(23.7 \%$, $32.9 \%$, respectively), but there was no significant association between case-fatality rate and gender. A total of $74.3 \%$ and $45.4 \%$ of patients at one- and six-month were functionally dependent. The majority $(88.9 \%)$ of diabetic patients were functionally dependent. Also, the one and six month recurrence rates of stroke patients were $15.7 \%$ and $23.2 \%$, respectively. For both one and six month post stroke more recurrence occurred from ischemic $(16.2 \%, 14.3 \%$, respectively) than from hemorrhagic $(24.5 \%, 19.5 \%$, respectively) strokes, but there was no significant association between the recurrence and stroke subtype $(P=0.691, P=0.367$, respectively).

Conclusion: The reported outcomes are relatively comparable to that reported in other developing countries, although it is still more than the rates of developed countries. Outcome measures can help to give information and develop guidelines for clinical practice and research.

Keywords: Stroke; Case fatality; Recurrence; Functional outcome.

\section{Introduction}

Stroke is one of the leading causes of death worldwide, and it is an increasing problem in developing countries, and $87 \%$ of stroke deaths occurring in developing countries. ${ }^{1-3}$ Stroke is the principal cause of disability, dependency and loss of social competence in the western world. The majority of strokes are of ischemic origin, and most ischemic strokes are due to athero-thrombosis. Clearly, a thorough knowledge of prognosis and effective secondary prevention strategies are of paramount importance for clinicians who care for stroke patients. ${ }^{4}$ The overall case fatality gives information about the severity of the stroke and may also reflect the efficacy of early management of acute stroke, is roughly $20 \%$ within the first month, and increases around 5\% per year. There is, however, a large variation in case fatality of stroke among populations; in the WHO Monitoring of Trends and Determinants in Cardiovascular Disease (MONICA) Stroke Study, the case-fatality of stroke varied between $12 \%$ in northern Sweden to $53 \%$ in Moscow in Russia. Generally, the case fatality was high in eastern European countries. In women, the difference in case fatality was greater than

* Department of Community Medicine, College of Medicine, Hawler Medical University, Erbil, Iraq. 
in men, ranging from $16 \%$ in Kuopio to $57 \%$ in Moscow. ${ }^{5}$ Changes in incidence and better survival on the downhill trend in stroke mortality are difficult to measure, due to the complexity of determining precisely the incidence of stroke. Stroke has a multifactorial origin and a plethora of putative and confirmed risk factors have been listed and tested in various types of studies. The assessment of the global epidemiology is severely hindered by the lack of any kind of data on stroke occurrence and risk factors in most populations in the world. Although more than $65 \%$ of deaths due to stroke occur in developing countries, studies of stroke epidemiology in these populations hardly exist. ${ }^{6}$ Outcomes measures can have different goals and according to the WHO classification, they may be measured at various levels. The purpose is to provide the results that measure not only therapeutic or technical success of rehabilitation but also the satisfaction of patient, as well as the patient's ability to function physically, emotionally, and socially. Outcome measures could be a study of cohorts of stroke patients in order to understand the clinical evolution of patients treated by specific drugs or techniques. This study was carried out to determine the one- and six-month case fatality, recurrence, and functional outcome of stroke patients in Erbil teaching hospitals.

\section{Methods}

This hospital-based prospective study was carried out between January $1^{\text {st }}, 2015$ and December $31^{\text {st }}, 2015$. A convenience sample of 293 newly diagnosed stroke patients by consultant internist and/or neurologist (based on clinical findings and confirmed by brain CT-scan and/or MRI) attending Erbil Teaching Hospitals in Iraq were included. A case was considered as a "stroke" according to the WHO definition. ${ }^{7}$ Cases discovered to be secondary to a brain tumor, or brain metastasis, or caused by trauma was excluded from the study. Brain imaging (CT-Scan and/or $\mathrm{MRI}$ ) was done for all patients to confirm the diagnosis and stroke subtype. The study protocol was approved by the scientific and ethical committees of College of Medicine at Hawler Medical University. Verbal informed consent obtained from all patients or their close relatives. Data collection was done by direct interview of the patient or their close relatives, including age, gender, marital status, history of hypertension and diabetes mellitus. Follow-up variables include patients' outcome (whether died or not), functional outcome and recurrent attack of stroke during six months period. Patients were followed-up and visited two times; first at one month and second at six month post stroke. If the patient was died, the case-fatality rate was calculated for the first and six months after stroke onset. If the patients were alive, they were examined for the grade of disability by modified Rankin scale (mRS) and also asked about any recurrent attack of stroke. The mRS was used to identify the functional outcome (the extent of disability after stroke). The $\mathrm{mRS}$ is a clinician-reported measure of disability that has usually been applied to evaluate recovery from stroke. The mRS consists of six-point scale ranging from zero to five. ${ }^{8}$ The mRS is used, worldwide, to assess functional outcome in patients with stroke. An independent state was defined as Rankin score of zero to two and score of three to five for dependent state. ${ }^{9}$ The statistical package for the social sciences (version 18.0) was used for data entry and analysis. Chi-square $\left(x^{2}\right)$ test was used to compare the proportions, and Student t-test was used to compare means of numerical variables. A $P$ value of $\leq 0.05$ was considered statistically significant.

\section{Results}

The sample included 293 patients; the mean age was $58.99 \pm 9.15$ years and age ranged from (35 to 74 years). The male proportion (152; 51.88\%) 
was slightly higher than female proportion $(141 ; 48.12 \%)$ with a male: female ratio of 1.08:1. The female patients were slightly older than male patients. The mean age's \pm SD was $59.09 \pm 8.80$ years for female and $58.89 \pm 9.48$ years for male patients. Table 1 shows that there was a significant difference between the means of age and years of education of patients for one-month $(P<0.001$ and 0.049 , respectively) and six-month case fatalities $(P<0.001$ and 0.009 , respectively). There was no significant difference between the mean ages of recurrent stroke patients for both one- month $(P=0.347)$ and six months $(P=0.598)$ post stroke. Results revealed that one and six months case fatality rates were $28.3 \%(83 / 293)$ and $37.5 \%$ (110/293), respectively. Although the rates in females (33.3\%, 42.6\%, respectively) were higher than that in males $(23.7 \%, 32.9 \%$, respectively), but there was no significant association between case-fatality rate and gender $(P=0.067, P=0.88)$. There was a significant association between one month case-fatality rate and marital status, hypertension, and ischemic stroke $(P=0.001,0.012$, and 0.034 , respectively). The case-fatality rate for both one and six months was higher in diabetic $(29.9 \%$, $37.7 \%$, respectively) than non diabetic patients $(27.8 \%, 37.5 \%$, respectively). There was no statistically significant

Table 1: Mean and standard deviation of age and years of formal education by stroke outcome

\begin{tabular}{|c|c|c|c|c|c|c|}
\hline \multirow{2}{*}{$\begin{array}{l}\text { Stroke outcome } \\
\text { Outcome }\end{array}$} & \multicolumn{2}{|c|}{$\begin{array}{l}\text { One month } \\
\text { Mean } \pm S D\end{array}$} & \multirow[t]{2}{*}{$P$ value } & \multicolumn{2}{|c|}{$\begin{array}{l}\text { Six month } \\
\text { Mean } \pm \text { SD }\end{array}$} & \multirow[t]{2}{*}{$P$ value } \\
\hline & Died & Alive & & Died & Alive & \\
\hline Age (years) & $62.24 \pm 7.24$ & $57.70 \pm 9.52$ & $<0.001$ & $62.60 \pm 7.05$ & $56.81 \pm 9.58$ & $<0.001$ \\
\hline Years of education & $1.98 \pm 3.93$ & $3.05 \pm 4.72$ & 0.049 & $1.90 \pm 3.85$ & $3.25 \pm 4.83$ & 0.009 \\
\hline Functional dependence & Dependent & Independent & & Dependent & Independent & \\
\hline Age (years) & $58.78 \pm 9.42$ & $54.57 \pm 9.16$ & 0.005 & $59.06 \pm 9.54$ & $54.95 \pm 9.26$ & 0.004 \\
\hline Years of education & $2.49 \pm 4.44$ & $4.67 \pm 5.15$ & 0.007 & $2.52 \pm 4.47$ & $3.86 \pm 5.05$ & 0.058 \\
\hline Recurrence & Yes & No & & Yes & No & \\
\hline Age (years) & $60.15 \pm 8.99$ & $58.77 \pm 9.18$ & 0.347 & $59.50 \pm 10.05$ & $58.83 \pm 8.87$ & 0.598 \\
\hline Years of education & $1.28 \pm 3.30$ & $3.02 \pm 4.68$ & 0.003 & $1.41 \pm 3.44$ & $3.15 \pm 4.74$ & 0.001 \\
\hline
\end{tabular}


association between diabetes and association between gender and the case-fatality rates $(P=0.726, P=0.980$, respectively) as shown in Table 2 . The results revealed that after one and six months from the onset of stroke, $74.3 \%$ $(156 / 210)$ and $45.4 \%(83 / 183)$ of patients were functionally dependent with a higher proportion of functional dependency in females $(79.8 \%)$ than in male stroke patients $(69.8 \%)$ at one month post stroke. However, there was no significant functional dependency rate for both one and six month post stroke. The majority $(85.25 \%)$ of single and widowed and $(88.9 \%)$ of diabetic stroke patients were functionally dependent one month post stroke. There was a significant association between functional dependence at one month with marital status and diabetes ( $P=0.02, P=0.004$, respectively). These findings are shown in Table 3.

Table 2: One and six month case-fatality rates.

\begin{tabular}{|c|c|c|c|c|}
\hline \multirow[b]{2}{*}{ Characteristic } & \multicolumn{4}{|c|}{ Case fatality rate } \\
\hline & $\begin{array}{c}\text { One month } \\
\text { No. (\%) }\end{array}$ & $P$ value & $\begin{array}{c}\text { Six month } \\
\text { No. }(\%)\end{array}$ & $P$ value \\
\hline $\begin{array}{l}\text { Gender } \\
\text { Male }(N=152) \\
\text { Female }(N=141)\end{array}$ & $\begin{array}{l}36(23.7) \\
47(33.3)\end{array}$ & 0.067 & $\begin{array}{l}50(32.9) \\
60(42.6)\end{array}$ & 0.088 \\
\hline Marital status & & & & \\
\hline $\begin{array}{l}\text { Single and widow }(\mathrm{N}=101) \\
\text { Married }(\mathrm{N}=192)\end{array}$ & $\begin{array}{l}40(39.6) \\
43(22.4)\end{array}$ & 0.001 & $\begin{array}{l}54(53.5) \\
56(29.2)\end{array}$ & $<0.001$ \\
\hline $\begin{array}{l}\text { Hypertension } \\
\text { Hypertensive }(\mathrm{N}=182) \\
\text { Not hypertensive }(\mathrm{N}=111)\end{array}$ & $\begin{array}{l}61(33.5) \\
22(19.8)\end{array}$ & 0.012 & $\begin{array}{l}79(43.4) \\
31(27.9)\end{array}$ & 0.008 \\
\hline $\begin{array}{l}\text { Diabetes mellitus } \\
\text { Diabetic }(\mathrm{N}=77) \\
\text { Not diabetic }(\mathrm{N}=216)\end{array}$ & $\begin{array}{l}23(29.9) \\
60(27.8)\end{array}$ & 0.726 & $\begin{array}{l}29(37.7) \\
81(37.5)\end{array}$ & 0.980 \\
\hline $\begin{array}{l}\text { Type of stroke } \\
\text { Ischemic }(\mathrm{N}=216) \\
\text { Hemorrhagic }(\mathrm{N}=77)\end{array}$ & $\begin{array}{l}54(25.0) \\
29(37.7)\end{array}$ & 0.034 & $\begin{array}{l}75(34.7) \\
35(45.5)\end{array}$ & 0.095 \\
\hline
\end{tabular}

Table 3: One and six month functional dependency rates.

\begin{tabular}{|c|c|c|c|c|}
\hline \multirow[b]{2}{*}{ Characteristic } & \multicolumn{4}{|c|}{ Dependency rate } \\
\hline & $\begin{array}{l}\text { One month } \\
\text { No. (\%) }\end{array}$ & $P$ value & $\begin{array}{l}\text { Six month } \\
\text { No. (\%) }\end{array}$ & $P$ value \\
\hline $\begin{array}{l}\text { Gender } \\
\text { Male } \\
\text { Female }\end{array}$ & $\begin{array}{c}81 / 116(69.8) \\
75 / 94(79.8)\end{array}$ & 0.101 & $\begin{array}{c}47 / 102(46.1) \\
36 / 81(44.4)\end{array}$ & 0.825 \\
\hline $\begin{array}{l}\text { Marital status } \\
\text { Single and widow } \\
\text { Married }\end{array}$ & $\begin{array}{c}52 / 61(85.25) \\
104 / 149(69.8)\end{array}$ & 0.020 & $\begin{array}{l}23 / 47(48.94) \\
60 / 136(44.1)\end{array}$ & 0.567 \\
\hline $\begin{array}{l}\text { Hypertension } \\
\text { Hypertensive } \\
\text { Not hypertensive }\end{array}$ & $\begin{array}{c}95 / 121(78.5) \\
61 / 89(68.5)\end{array}$ & 0.102 & $\begin{array}{c}49 / 103(47.6) \\
34 / 80(42.5)\end{array}$ & 0.494 \\
\hline $\begin{array}{l}\text { Diabetes mellitus } \\
\text { Diabetic } \\
\text { Not diabetic }\end{array}$ & $\begin{array}{c}48 / 54(88.9) \\
108 / 156(69.2)\end{array}$ & 0.004 & $\begin{array}{c}27 / 48(56.3) \\
56 / 135(41.5)\end{array}$ & 0.078 \\
\hline $\begin{array}{l}\text { Type of stroke } \\
\text { Ischemic } \\
\text { Hemorrhagic }\end{array}$ & $\begin{array}{c}116 / 162(71.6) \\
40 / 48(83.3)\end{array}$ & 0.102 & $\begin{array}{c}60 / 141(42.6) \\
23 / 42(54.8)\end{array}$ & 0.163 \\
\hline
\end{tabular}


https://doi.org/10.15218/zjms.2018.011

The study findings revealed one and six months recurrence rates of stroke patients were $15.7 \% \quad(46 / 293)$ and $23.2 \%(68 / 293)$, respectively. There is no statistically significant association between the recurrence rate for both one and six month post stroke with gender, marital status, hypertension, diabetes. For both one and six month post stroke more recurrence occurred from ischemic $(16.2 \%, 14.3 \%$, respectively) than from hemorrhagic $(24.5 \%, 19.5 \%$, respectively) strokes. However, there was no significant association between one and six-month recurrences of stroke and stroke subtype ( $P=0.69$ and $P=0.367$, respectively), as shown in Table 4.

\section{Discussion}

In many developing countries, the incidence of stroke is rising because of the adoption of less healthy lifestyles. About $20 \%$ of acute stroke patients will die within a month of the event, and at least half of those who survive will be left with a physical disability. ${ }^{10}$ In a study conducted in Australia, it has been reported that within one year of a stroke, around $37 \%$ will die and $10 \%$ will experience a recurrent stroke. ${ }^{11}$ The one month case fatality rate in the current study was $28.3 \%$, while it was $23.7 \%$ in a previous study in Erbil, ${ }^{12}$ $27.2 \%$ in India, ${ }^{13} 23.3 \%$ in Ukraine, ${ }^{14}$ $20.3 \%$ in Malaysia, ${ }^{15}$ and $31.5 \%$ in Iran, ${ }^{16} 38 \%$ in Senegal. ${ }^{17}$ Stroke mortality is projected to increase more rapidly in developing countries than in developed countries due to demographic and epidemiological shifts which resulted in stroke becoming a major health problem. ${ }^{2}$ The six-month case-fatality rate revealed by this study $(37.5 \%)$ is higher than that reported in other countries. In Australia, this figure has been reported to vary between $23.9 \%$ and $35.5 \%$ in different months. ${ }^{18}$ The higher proportion of deaths for both one-month and six-month in females revealed by this study which is consistent with other studies done in Sweden $^{19}$ and Italy $^{20}$ may be due to the reported high proportion of risk factors (especially hypertension) in females. Risk of stroke is higher for older and low-income women and the death rate of stroke more

Table 4: One and six month recurrence rates.

\begin{tabular}{|c|c|c|c|c|}
\hline \multirow[b]{2}{*}{ Characteristic } & \multicolumn{4}{|c|}{ Recurrence rate } \\
\hline & $\begin{array}{l}\text { One month } \\
\text { No. (\%) }\end{array}$ & $P$ value & $\begin{array}{c}\text { Six month } \\
\text { No. (\%) }\end{array}$ & $P$ value \\
\hline \multicolumn{5}{|l|}{ Gender } \\
\hline Female $(N=141)$ & $27(19.1)$ & 0.118 & $37(26.2)$ & 0.236 \\
\hline \multicolumn{5}{|l|}{ Marital status } \\
\hline Single and widow $(N=101)$ & $19(18.8)$ & \multirow[b]{2}{*}{0.288} & $27(26.7)$ & \multirow[b]{2}{*}{0.300} \\
\hline Married $(\mathrm{N}=192)$ & $27(14.1)$ & & $41(21.4)$ & \\
\hline \multicolumn{5}{|l|}{ Hypertension } \\
\hline Hypertensive ( $\mathrm{N}=182)$ & $28(15.4)$ & \multirow{2}{*}{0.849} & $41(22.5)$ & \multirow{2}{*}{0.724} \\
\hline Not hypertensive $(\mathrm{N}=111)$ & $18(16.2)$ & & $27(24.3)$ & \\
\hline \multicolumn{5}{|l|}{ Diabetes mellitus } \\
\hline Diabetic $(N=77)$ & $14(18.2)$ & \multirow[b]{2}{*}{0.486} & $19(24.7)$ & \multirow[b]{2}{*}{0.722} \\
\hline Not diabetic $(\mathrm{N}=216)$ & $32(14.8)$ & & $49(22.7)$ & \\
\hline \multicolumn{5}{|l|}{ Type of stroke } \\
\hline Ischemic $(\mathrm{N}=216)$ & $35(16.2)$ & \multirow[b]{2}{*}{0.691} & $53(24.5)$ & \multirow[b]{2}{*}{0.367} \\
\hline Hemorrhagic $(N=77)$ & $11(14.3)$ & & $15(19.5)$ & \\
\hline
\end{tabular}


https://doi.org/10.15218/zjms.2018.011

than triples with each added decade of life after 45 years age. ${ }^{21}$ This study revealed that there is a higher proportion of deaths from hemorrhagic than ischemic stroke, a finding which is consistent with the studies done in Martinique $(37.3 \%$ vs. $15.8 \%){ }^{22}$ and in Croatia (54.3\% vs. $25.8 \%) .{ }^{23}$ The higher mortality in hemorrhagic strokes might be due to the extension of bleeding to the large area of brain tissue and development of increased intracranial pressure and consequent brain edema. The higher proportion of functional dependency in females than in male stroke patients was not statistically significant, which agrees with the findings of the study done in Kerala, India that revealed no significant difference in the functional outcome between males and females, and nearly $60 \%$ of patients were significantly disabled 1 month post-stroke. ${ }^{13}$ Older age was related to a poorer functional outcome in the ADL/physical function domain. Moreover, increased age was related to a more severe stroke and worse recovery that may explain the low ADL and physical function scores. ${ }^{24}$ Elsewhere, findings related to age have been somewhat inconsistent. In other studies, younger patients have had better post-stroke ADL. ${ }^{25}$ It is expected that around $60 \%$ of stroke survivors are likely to recover independence, and $75 \%$ to walk independently. Another study showed that of those who survive, about $51 \%$ are disabled in various activities of daily living. ${ }^{26}$ People dealing with stroke treatment are more worried about adaptation to disability and ability to perform activities of daily living, because the major goal of stroke rehabilitation is to return to independence in ADL. ${ }^{27}$ Previous studies have established that advanced age and diabetes are predictors of recurrence, ${ }^{28}$ and also revealed that lowering blood pressure in stroke survivors can reduce the risk for both first and recurrent stroke by $40 \% .{ }^{29}$ Unavailability of special stroke unit in Erbil teaching hospitals might be another factor for poor outcomes. For people who were admitted to a stroke unit at the time of their index stroke, the risk of recurrent stroke was reduced by $16 \%$, while patients transferred to another hospital at first admission had a $25 \%$ increased risk of recurrence. It has been shown that treatment in stroke units can improve outcomes, independence and capacity to live at home. ${ }^{28}$

\section{Conclusion}

The reported outcomes are relatively comparable to that reported in other developing countries, although it is still more than the rates of developed countries. Establishment of a stroke unit in Erbil teaching hospitals to improve the outcome of stroke patients is recommended. Finally, outcome measures can help to give information and develop guidelines for clinical practice and research.

\section{Competing interests}

The author declares that he has no competing interests.

\section{References}

1. Lopez AD, Mathers CD, Ezzati M, Jamison DT, Murray CJL. Global and regional burden of disease and risk factors, 2001: Systematic analysis of population health data. Lancet 2006; 367(9524):1747-57.

2. Strong K, Mathers C, Bonita R. Preventing stroke: saving lives around the world. Lancet Neurol 2007; 6(2):182-7.

3. Beaglehole R, Ebrahim S, Reddy S, Voute J, Leeder S. Prevention of chronic diseases: A call to action. Lancet 2007; 370 (9605):2152-7.

4. Bousser MG, Bogousslavsky J. Advances in stroke prevention. Cerebrovasc Dis 2003; 16 (suppl 1):1-2.

5. Sarti C, Stegmayr B, Tolonen $H$, Mahonen $M$, Tuomilehto J, Asplund $\mathrm{K}$. Are changes in mortality from stroke caused by changes in stroke event rates or case fatality? Results from the WHO MONICA Project. Stroke 2003; 34(8):1833-40.

6. Sarti C, Rastenyte D, Cepaitis Z, Tuomilehto J. International trends in mortality from stroke, 1968 to 1994. Stroke 2000; 31(7):1588-601.

7. Park K. Park's textbook of preventive and social medicine. $23^{\text {rd }}$ ed. Jabalpur (India): Banarsidas Bhanot Publishers; 2015. 
8. Banks JL, Marotta CA. Outcomes validity and reliability of the modified Rankin scale: Implications for stroke clinical trials: A literature review and synthesis. Stroke 2007; 38:1091-6.

9. Nencini P, Nesi M. Neurological functional scales: National institute of health stroke scale (NIHSS), modified rankin scale, glasgow scale. Cerebrovasc Dis 2008; 26 (suppl 2):1-29.

10. Allen CMC, Lueck CJ, Dennis M. Neurological diseases. In: Colledge NR, Walker BR, Ralston SH. Davidson's principles and practice of medicine. $21^{\text {st }}$ ed. Edinburgh: Churchill Livingstone; 2010.

11. Dewey HM, Thrift AG, Mihalopoulos C, Carter R, Macdonell RA, McNeil JJ, et al. The cost of stroke in Australia from a societal perspective: Results from the north east Melbourne stroke incidence study (NEMESIS). Stroke 2001; 32:2409-16.

12. Ismail KH, Al-Tawil NG, Al-Hadithi TS. Case fatality rate of first-ever stroke in Erbil city. Zanco J Med Sci 2010; 14 (Special issue 1):14-9.

13. Sridharan SE, Unnikrishnan JP, Sajith S, Sylaja PN, Dinesh NS, Sankara SP, et al. Incidence, types, risk factors, and outcome of stroke in a developing country: The Trivandrum, Kerala, India. Stroke 2009; 40 (4):1212-8.

14. Mihalka L, Smolanka V, Bulecza B, Mulesa S, Bereczki D. A population study of stroke in West Ukraine: Incidence, stroke services, and 30-day case fatality. Stroke 2001; 32:2227-31.

15. Ong TZ, Raymond AA. Risk factors for stroke and predictors of one-month mortality. Singapore Med J 2002; 43:517-21.

16. Oveisgharan S, Sarrafzadegan N, Shirani S, Hosseini S, Hasanzadeh P, Khosravi A. Stroke in Isfahan, Iran: Hospital admission and 28-day case fatality rate. Cerebrovasc Dis 2007; 24:4959.

17. Sagui E, M'Baye PS, Dubecq C, Fall KB, Niang A, Gning S, et al. Ischemic and hemorrhagic strokes in Dakar, Senegal: A hospital-based study. Stroke 2005; 36:1844-7.

18. Wang Y, Levi CR, Attia JR, D'Este CA, Spratt N, Fisher J. Seasonal variation in stroke in the Hunter region, Australia: A 5-year hospital-based study, 1995-2000. Stroke 2003; 34:1144-50.

19. Hallström B, Jönsson AC, Nerbrand C, Norrving $B$, Lindgren A. Stroke incidence and survival in the beginning of the $21^{\text {st }}$ century in Southern Sweden. Comparisons with the late $20^{\text {th }}$ century and projections into the future. Stroke 2008; 39:10-5.

20. Musolino R, La Spina P, Serra S, Postorino P, Calabró S, Savica R, et al. First-ever stroke incidence and 30-day case fatality in the Sicilian Aeolian Archipelago, Italy. Stroke 2005; 36 (12): 2738-41.

21. Minino AM, Heron MP, Murphy SL, Kochanek KD. Deaths: Final data for 2004. Natl Vital Stat Rep 2007; 55 (19):1-119.
22. Smadja D, Cabre P, May F, Fanon J, Renee-Corail P, Riocreux C, et al. Epidemiology of stroke in Martinique, French West Indies. Part I. Methodology, incidence, and 30-day case fatality rate. Stroke 2001; 32:2741-7.

23. Ivanusa $M$, Ivanusa $Z$. Risk factors and in-hospital outcomes in stroke and myocardial infarction patients. BMC Public Health 2004; 4:26.

24. Heikinheimo T, Chimbayo D, Kumwenda JJ, Kampondeni S, Allain TJ. Stroke outcomes in Malawi, a country with high prevalence of a prospective follow-up study. PLoS One 2012; 7 (3):e33765.

25. Muli G, Rhoda A. Quality of life amongst young adults with stroke living in Kenya. Afr Health Sci 2013; 13(3):632-8.

26. Srikanth VK, Anderson JF, Donnan GA, Saling MM, Didus E, Alpitsis $R$, et al. Progressive dementia after first-ever stroke. A communitybased follow-up study. Neurology 2004; 63:78592.

27. Bogousslavsky J. Long-term effects of stroke. Marcel Dekker, Inc.: New York. Bassel; 2002.

28. Lee $\mathrm{AH}$, Somerford PJ, Yau KKW. Risk factors for ischaemic stroke recurrence after hospitalisation. MJA 2004; 181(5):244-6.

29. Joubert J, Reid C, Barton D, Cumming $T$, Mc Lean A, Joubert $L$, et al. Integrated care improves risk-factor modification after stroke: Initial results of the integrated care for the reduction of secondary stroke model. J Neurol Neurosurg Psychiatry 2009; 80:279-84. 